\title{
Disruption of Moral Reasoning and Moral Judgment: Moral Injury and Healing Through Forgiveness
}

\section{Richard La Fleur, PhD, CMHIMP}

Department of Anthropology, Psychology and Sociology, University of West Georgia, United States.

\begin{abstract}
Article Details
Article Type: Review Article

Received date: $02^{\text {nd }}$ March, 2021

Accepted date: $10^{\text {th }}$ April, 2021

Published date: $17^{\text {th }}$ April, 2021 University of West Georgia, United States. E-mail: rlafleur@westga.edu credited.

Abstract

Although morality (systemic judgment of determining right or wrong), has been taught, researched and written about over the decades, society has been faced with the challenges of a questionable moral structure and a plethora of moral injuries. This paper reviews current literature and research about moral injury as well as the structure on which morality is founded. Current research shows that one of the consequences of an irreconcilable moral belief is moral injury or a soul injury, (coined by Dr. Marvin Westwood in a recent lecture at St. Thomas University), with symptoms that are similar to PTSD and other mental illnesses or disorders. By focusing on moral injury as a deep psychological and spiritual wound, forgiveness as a theological and spiritual approach, is the most effective framework to address the wound of moral injury.
\end{abstract}

"Corresponding Author: Richard La Fleur, PhD, CMHIMP, Department of Anthropology, Psychology and Sociology,

Citation: La Fleur, R. (2021). Disruption of Moral Reasoning and Moral Judgment: Moral Injury and Healing Through Forgiveness. J Ment Health Soc Behav 3(1):139. https://doi.org/10.33790/jmhsb110039

Copyright: (C2021, This is an open-access article distributed under the terms of the Creative Commons Attribution License $\underline{4.0}$, which permits unrestricted use, distribution, and reproduction in any medium, provided the original author and source are

Key Words: Moral Injury, PTSD, Psychology, Spirituality, Narrative, Mental Illness, Well-Being, Morality Soul Injury

\section{Introduction}

Moral injury has been researched and discussed on many different platforms and forums, without a more centralized and in depth examination or understanding. Shay [1] introduced moral injury as a betrayal of what is morally correct. Betrayal includes leadership failures, betrayed by friends and family, failure to live up to one's moral standards and beliefs and in the case of soldiers, feeling betrayed by the civilian world. For the most part, warriors and soldiers have been faced with the challenges of moral and ethical dilemmas with unconventional situations that amplifies life's challenges. Morally injurious situations and events that transgress deeply held moral beliefs and expectations, have been historically present for many generations. To better understand the extent of moral and ethical dilemmas, it seems important to understand the perspective of the experiencer and their story. As stated by Randall [2], "I suggested awhile back that we can envision our lives as vast, ever changing narrative worlds that we're squarely in the middle of, as author (or co-author), narrator, protagonist, and reader more or less at once, making them up as we go along always from the inside" (p. 65). It seems difficult to remain ambivalent within the narrative to consider how to act or respond (traumatic experiences), outside of the locus of control, limited by the circumstance that leads to an imbalance within the self.

This paper is designed to explore the foundation of moral reasoning and the acquisition of a belief system whereby judgment becomes a part of the self. Additionally, further exposure to moral injury and the consequences of moral injury, will be guided by the work and life of Primo Levi. As a Spiritual Counselor, I am also interested in the wellbeing and healing through the lens of forgiveness and how it may add value and diminish internal suffering.

\section{Moral Reasoning and Judgement}

It seems as though moral reasoning is a precursor to moral judgment, with specific attention given to the reasons and conditions in which reasoning occurs [3-10]. Many psychologists subscribe to the fact that all moral judgments are produced by moral reasoning $[11,12]$. With this in mind, most people cannot fully explain their process for moral reasoning and judgments and have come to accept that most of their moral decisions are based on past experiences. Logical deduction and emotional intelligence, especially through the lens of disgust or happiness are part of the structure of morality [1317]. Although Piaget and Kohlberg [12, 18] gave us the role of moral reasoning in the early stages of development, more recent findings by Bucciarella et al. [19], defines reasoning as "any systematic mental process that constructs or evaluates implications from premises of some sort" (p. 123), and moral reasoning as reasoning that involves "deontic propositions" as premises, which are propositions that "concern what you may, should, and should not do or else leave undone" (p. 124). For Bucciarelli et al, [19], moral reasoning may be either an intentional and conscious process or a non-intentional and nonconscious practice, as long as the process is systematic (or logical) and a clear retreat from the view that moral reasoning is always a conscious process.

Given this thought process, it seems safe to say moral reasoning is the conversion (given the parameters above) of information, in order to arrive at a judgment of a given situation or circumstance. Therefore, moral reasoning is intentional, effortful and controllable and the person reasoning is aware of what is going on. But what happens when the person is in a high stake or high risk situation and does not have control of the situation or people around them? In these high-stake situations, unseen wounds are more common occurrences and many times go unnoticed, leading to moral injuries.

\section{What is Moral Injury?}

Humans are moral creatures and ask moral questions to develop a system of beliefs and values that makes sense of place in the world [18]. It is through the system of beliefs and values that moral decisions are made and when damage is done to one's moral compass or conscience, the injury occurs.

Jonathon Shay [1] introduced the term moral injury in response to his work with veterans and the betrayal they felt from leadership malpractice. It was more recently discussed by Brock and Lettini, [20] as a direct result of soldiers experiencing military life or being deployed to a hot zone. After seeing and experiencing challenging events and situations as a result of war, many soldiers struggle with the difficulty of reintegrating from military life to civilian life.

Moral injury is often referred to as a "construct" that describes JMHSB, an open access journal 
the "disruption in an individual's confidence and expectations about one's own or other's motivation and capacity to behave in a just and ethical manner" [21] (p. 9). Litz et al, [22] goes on to describe moral injury as "the inability to contextualize or justify personal actions or the actions of others and the unsuccessful accommodation of these... experiences into pre-existing moral schemas" (p. 705). Shay [23] emphasized leadership failure as a betrayal of what is right and just, by a person who is the highest authority in a high-stakes, and stressful situation.

While moral injury is mostly connected to the military population, there is an increasing focus of discussion and study cross-disciplinary, to better understand moral injury in other populations that result in anguish, anger, alienation and isolation which can lead to mental illnesses. With that in mind, questioning a person's beliefs and values against conscious actions, events or circumstances contrary to those said beliefs and values (maybe what I did or said or didn't do or didn't say was wrong), can lead a person to experience moral injury [24]. Therefore, moral injury may be purported as the shattering or collapse of a person's moral foundations especially in partially extreme conditions [24]. Moral injury can be viewed as an inner soul wound that disrupts a person's identity and disconnects their morality and place in society. Moral injury then, is a deeply rooted trauma with many consequences.

While the symptoms of moral injury may not present immediately, it can occur in confronting dangerous situations when one has no good choice. One such condition is being in war. War is morally compromising because carrying out or completing the mission is the most important part of being in a war. In the case of war, moral injury has been defined as the emotional, spiritual and moral consequences of committing and/or observing others commit transgressions of deeply held moral values, during combat or combat-related circumstances [22].

Moral injury can also be implicated when one experiences extreme loss, encounters repeated exposure to violent death and gore, or witnesses something that is profoundly disturbing to one's inner sense of what is right or humane [22]. Morality can be considered the fabric of one's humanness that is the soul of the self.

To take more general approach, moral injury is not unique to service members. Although its etiology is foundational and based on various military acts or the lack of action that transgress deeply held moral beliefs, moral injury can be seen in the everyday inner conflicts that lead to anger, or guilt and shame [25]. Feelings of shame and guilt as well as embarrassment, are connecting points to moral standards and behaviors. They also show connectedness to individuals and groups, as well doing the right thing [26]. To be clear, moral injury occurs when individuals makes a moral judgment about a person or situation and then does not act accordingly [27]. This tends to happen when power is wielded in an unhealthy manner (individual or organization), as stated before, war. Moral injury involves a deeper spiritual and emotional wound and is unique to those who witness or experience intense human suffering and/or cruelty [22]. Internal conflict that results from acting in a manner contradictory to one's moral beliefs can result in mental illnesses such as anxiety, depression, suicidal thoughts and social withdrawal.

At times, it is not easy to accept or talk about inner moral anguish in fear of being exposed and vulnerable [28]. Moral injury is perhaps most appropriately described as injury that results from our inner moral conflict more specifically, that sort of conflict that derives from one having acted or having failed to act in agreement with one's core beliefs, values, and ideals [29]. In this respect, moral injury inevitably involves a measure of moral transgression. The transgression in question, rather than being limited to this or that moral principle, cuts to the heart or core of one's very identity as a moral being (one's sense of morality). While there is no formal definition for moral injury [30], for this reason, it can be argued, moral injury is also a spiritual injury. Spiritual injury may be understood to be "our response to an event caused by self, or an event beyond our control, that damages our relationship with God, self and others, and alienates us from that which gives meaning to our lives" [31].

\section{A Closer Look at Moral Injury - Primo Levi}

The life of Primo Levi [32], a holocaust survivor, in his writing, The Drowned and the Saved, he gives us a deeper insight into the heart of moral injury and exposes just how painful it can be. Levi's writing goes far beyond a recapitulation of the concentration camp experience and is his experience of reflecting on the past, which can be seen as a complex and at times, a painful experience.

Memory is an important part of understanding moral injury. While many still tend to think about memory from a factual perspective, in most instances, the things we remember are not really how they happened. Therefore, remembering can lead us to believe something that did not actually happen. In the chapter, "The Memory of the Offense", Levi [32] writes, "The memories which lie within us, are not carved in stone" (p. 23). Levi [32] alludes to the challenges of memory under normal conditions, but after being injured or experience suffering, "almost all the factors that can obliterate or deform the mnemonic record are at work: the memory of a trauma suffered or inflicted is itself traumatic because recalling it is painful or at least disturbing" [32], (p. 24). This is important to note because the factors of time, distance and emotions are at work altering the event as it is being stored.

In many cases, moral injury causes a person to "block out the memory so as not to renew the pain; the person who has inflicted the wound pushed the memory deep down, to be rid of it, to alleviate the feeling of guilt" [32], (p. 24). It is also important to note that the pain of moral injury can be experienced by the perpetrator as well as the victim. As Levi [32] writes, "...we are dealing with a paradoxical analogy between victim and oppressor". Levi [32] continues, “... both are in the same trap, but it is the oppressor, and he alone, who has prepared it and activated it, and if he suffers from this, it is right that he should suffer; and it is iniquitous that the victim should suffer from it, as he: does indeed suffer from it, even at a distance of decades" (p. 24). For some perpetrators, the wounds of moral injury are deep and painful yet in some cases may not be able to be healed.

In dealing with moral injury, the memory of the offense is met with a defense; finding a way to evade responsibility or justify why or give an explanation of ill treatment, as was the case of many guards of the holocaust. For some the common response was "I did it because I was ordered to; others (my superiors) have committed acts worse than mine". Levi [32] goes on to write, "For anyone who reads these justifications the first reaction is revulsion: they lie, they cannot believe they will be believed, they cannot see the imbalance between their excuses and the enormity of the pain and death they have caused. They lie knowing that they are lying: they are in bad faith" (p. 26). For Levi [32], not facing the truth of the offense may not be as painful as facing the reality of the things that were or were not done. Moral injury seems to entail coming face to face with the truth. For many of the guards it was easier to deny the truth rather than accept it. Accepting the truth is often times less desirable and it seems easier to fabricate a different reality. Levi [32] writes,

The past is a burden to them; they feel repugnance for things done or suffered and tend to replace them with others. The substitution may begin in full awareness, with invented scenario, mendacious, restored, but less painful than the real one; they repeat the description to others but also to themselves, and the distinction between true and false progressively loses its contours, and man ends by fully believing the story he has told so many times and continues to tell, polishing and retouching here and there the details which are least credible or incongruous or incompatible with the acquired picture of historically accepted events: initial bad faith has become good faith (p. 27). 
In the face of moral injury, 'polishing' and 'retouching' the story, reduces the intensity enormity of how one may experience and respond to moral injury. While the story may seem less tragic or unimaginable to the perpetrator and those closest to them, the truth still lies within the self. Changing the story can have a permanent effect on the story-teller and in some ways, change their identity. It seems that the more distorted the truth is, the more distant it becomes. This then becomes the reality of living in denial; an ignorance of the truth. Maybe it is one way to deal with or cope with moral injury and the pain of the past. Levi writes about Louis Darquier de Pellepoix, who served as commissioner of Jewish affairs close to 1942, and how his denial became his reality. He was personally responsible for the deportation of a myriad of heinous acts against humanity. Levi [32] writes,

Darquier denies everything: the photographs of piles of corpses are montages; the statistics of millions of dead were fabricated by the Jews, always greedy for publicity, commiseration, and indemnities: there may perhaps have been deportations (he would have found it difficult to dispute them: his signature appears at the foot of too many letters giving orders for these very deportations, even of children), but he did not know where to or with what results; there were, it is true, gas chambers in Auschwitz, but only to kill lice, and anyway (note the coherence!) they were built for propaganda purposes after the end of the war (p. 27).

Darquier lived an undisturbed life by rejecting the truth. By rejecting the truth, one can avoid the intense pain of moral injury. Facing the truth "requires a decent sincerity or truthfulness with oneself; it demands a continuous intellectual and moral effort" [33], (p. 28). Levi asks a pertinent question, "How can such an effort be expected from men like Darquier?" (p. 28). For many, this is the question that probes at the core of considering the humanity of the other [34].

Moral injury is the recognition of transgression as well as embracing the humanity of the other. Many of the Nazi militia were, "educated, in absolute obedience, hierarchy, nationalism; we have been imbued with slogans, intoxicated with ceremonies and demonstrations; we have been taught that the only justice was that which was to the advantage of our people and that the only truth was the words of the Leader" [32], (p. 28). Ignoring or negating the other by only acknowledging "the advantage of our people", is one way to negate the presence of the other. This way of thinking may inhibit one's ability to see the humanity of the other, thus treat the other an object rather than a human being. The memory of the transgression to the other was ignored and unimportant. Instead, the words of the "Leader" became the moral compass of many guards, relieving them of all responsibility for the other.

For many, "The decisions were not ours because the regime in which we grew up did not permit autonomous decisions: others have decided for us, and that was the only way it could have happened because our ability to decide had been amputated. Therefore, we are not responsible and cannot be punished" [32], (p. 29). Eluding responsibility negated their ability to feel guilt and shame thus distancing themselves from moral injury and truth. As Levi [32] writes, "They too, so strong in the face of others' suffering, when fate put them before judges, before the death they deserved, built a convenient past for themselves and ended by believing in it..." (p. 29). By believing in the "built convenient past" it became impossible to answer the questions, "Why did you do this?" or "What were you thinking as you did it?" For Levi [32], " no reliable answers exist, because states of mind are by nature liable and even more liable is the memory of them" (p. 30). Denying the existence of the past and the acts committed can be intentional and in many cases, guards "expelled the harmful memory as one expels an excretion or parasite" (p. 30), thus suppressing the reality between 'good and bad faith', a dismissal of moral injury. However, as unfair as it may seem to suppress the reality of truth, so too is to, "defend oneself against the invasion of burdensome memories" and to, "impede their entry" Levi [32], (p. 31). Levi [32]goes on to write, "It is easier to deny entry to a memory than to free oneself from it after it has been recorded" (p. 31).

This method of distorting the truth of the event and creating a distraction so that the memory cannot be recalled was employed by the Nazi commanders. This can be a clear indication that reconnecting to the truth of certain realities, can lead to consequences that can take us past shame and guilt. The consequences of moral injury are in many cases beyond our control. It can be interpreted in many of Hitler's biographies that he, denied his subjects any access to truth, contaminating their morality and their memory. But, to a degree which gradually increased and attained complete paranoia in the Bunker, he barred the path of truth to himself as well. Like all gamblers, Hitler erected around himself, a stage set woven of superstitious lies and in which he ended by believing with the same fanatical faith that he demanded from every German. His collapse was not only a salvation for mankind, but also a demonstration of the price to be paid when one dismembers the truth [32], (p. 32).

Dismembering the truth and such disregard for the truth has devastating consequences as was experienced by Hitler and many others. Moral injury can be as devastating when it is acknowledged.

\section{Moral Lateness}

To take a more recent example of moral injury, we might turn to the work of Mark Freeman, author of Hindsight: The Promise and Peril of Looking Backward [35], and his interpretation of moral injury in the life of Primo Levi. In his writing, Freeman [35] wrote about the temporal nature of moral injury, which he called "moral lateness" ( $p$. 69). The idea of moral lateness occurs when a person looks back at their past and becomes aware of their actions or in some cases, lack of action and coming to accept it. As we remember a memory or experience, "one can look back upon an earlier experience or set of experiences and find things in them that either could or would not be seen at the time" [35], (p. 69). In some cases, during the heat of the moment or in the caught-up-ness of the event, we tend to miss things that are important or the parts of the memory that are morally injurious to us. As stated before, at times we tend to fabricate the past to rationalize how and why we did or did not do, which may have been contrary to what our moral compass was telling us to do. Even in the present, "I can convince myself, quite spontaneously, that what I am doing is justified, even right, good" [35], (p. 69). But, in the midst of trying to justify our present, as time goes on, "after the dust has cleared, I may see it all a new, with painful clarity" (p. 69).

Clarity opens the possibility for a truth to emerge, as was the experience of Levi as he explored some of his behaviors as a prisoner in the concentration camps. Sometimes admitting the truths of our past can show the imperfections of our lives. Having to believe and come to terms with one's own humanness as time passes by, is foundational for moral lateness or moral injury. While Levi was in fact a prisoner and one who was tortured at the hands of Nazi guards, his life was a reminder of our moral capacities and potentials as human beings. At times the delay and distance of time can cause a person to even deny the experience altogether and "disturb the peace of one's illusions" [35], (p. 73). So, what happens when to our memory or our story when it is disturbed? Freeman [35] writes, “... the memory in question becomes subservient to narrative, which has its own conventional, culture-specific norms, rules, and expectation. Add to this the dynamic dimension about which Levi speaks-the need to protect or defend, to offer a story, to others and to oneself, that has some justification to it-and the entire situation becomes that much more dangerous and pernicious. From this perspective, therefore, hindsight is seen to entail a dissolution or deformation of past realities.

As one moves away from the experiences in question, the picture 
becomes vaguer, blurrier, more susceptible to standardized-and sanitized-renditions" (p. 73-74). In other words, looking at the past and seeing the things that one could not be seen and moving closer to the event, not away from it. "The fact is, there is much that can be seen in retrospect that boggles the mind and shatters the spirit" [35], (p. 74). Shattering of the spirit seems to be one of the key components of accepting the truth and then becomes the inner conflict of moral or moral lateness. This inner conflict or anguish as Levi calls it, can bring on feelings of guilt and shame. With that in mind, it can be argued that the central vehicle for such healing may be looking towards theology or ethics, that centers around the notion of forgiveness (self and others), for what one has or has not done, and, perhaps even more importantly, by oneself [36].

\section{Forgiveness}

In his book, The Forgiving Self, Robert Karen [37] wrote, "Forgiveness is an aspect of the workings of love. It can be a bridge back from hatred and alienation as well as liberation from two kinds of hell: bitterness and victimhood on one side; guilt, shame and self-recrimination on the other" (p. 5). The desire to repair broken relationships either through forgiveness, apologizing for doing wrong or a gesture to close the gap between the participants is innate to human nature. Karen [37] writes, "The need to forgive-which may grow out of understanding, gratitude, sympathy, regret over the hurt one has caused, or simply a wish to reunite-may be as strong as the need to be forgiven, even if it comes upon us more subtly" (p. 5). This maybe very applicable to the well known story of the Prodigal Son. however in the case of moral injury self-forgiveness seems to be a crucial part of the process of forgiveness.

Moral injury calls into question the inner conflict, which invites us to the inner process of self-reflection. Self-reflection is in part what Freeman [35] referred to as, "reflective pauses" (p. 4). As we self-reflect, "moment following moment, and then pause to see what's being said, armed now with that measure of distance that might allow me to see things a bit more clearly" (p.4). At the core of self-reflection is self-understanding and clarity, which "has hindsight at its very core" (p. 4). According to Freeman [35], hindsight is, "the process of looking back over the terrain of the past from the standpoint of the present and either seeing things anew or drawing "connections"...that could not possibly be drawn during the course of ongoing moments but only in retrospect" (p. 4). In the case of moral injury, seeing things anew and making the connections to what was and how one is, connects the events of the past to the present. Hindsight is about the past and how one relates to the events of the past and how the past connects to the present.

Self-reflection seems to be the ability to make the connections from the past to the present and then accept it as the present reality. At times, it can be painful to recall the narrative of the past. Recalling the narratives of the past can ensue thoughts and feelings of betrayal, our insensitivity, cruelty, selfishness, humiliation and letting others down to name a few. In that same vein, how are these feelings and thoughts related to our own self? The need to be forgiven (self and other) is fundamental and an important part of our lives [37]. Knowing that we are in need of and need to forgive can be difficult to accept. It is the gaining of a new perspective, which is one of the roles of hindsight, to shape and deepen the moral life of a person [35]. The need for selfforgiveness may be as strong as the need to be forgiven. However, the "forgiving self can be hard to locate and the grudge state of devilishly hard time to let go of especially when we feel a bitter right to hold on to it..." [37], (p. 8). After reflecting and responding, it seems easy to blame ourselves out of necessity, because partly we are trying to defend self against shame. As stated earlier, moral injury and shame are closely related because of the behaviors that ensue after one experiences moral injury. However, in a culture of blaming, it is difficult to embrace our "murderousness, selfishness, greed, envy, because all of these very human feelings states have been made a source of so much guilt and shame that they lead at once to total condemnation and self-rejection" [37], (p. 119). This can cause us to negate self-care and can prevent us from seeing or coming to know a new perspective. Condemnation and self-rejection can lead to a defense that causes a person to ignore the responsibility of acknowledging ownership of the wrong, therefore self-blaming becomes a downward spiral. By this I mean, it can be easy to blame oneself for the event or situation as in the case of a morally injurious situation, but holding oneself responsible (not dominated by guilt and shame), opens the possibility for self-forgiveness and then the ability to receive forgiveness from self.

Sometimes it becomes too difficult to ignore the obvious and reject what it means to be human. Sometime we are called to regain our humanness and move beyond what may seem comfortable, transcend our humanity. Maybe, it requires us to move beyond our humanity and look to the spiritual as noted by Levi [33], "the saving force of their faith" (p. 146). Levi [33] continued to write, "Their universe (believers) was vaster than ours, more extended in space and time, above all more comprehensible: they had a key and a point of leverage, a millennial tomorrow so that there might be a sense to sacrificing themselves, a place in heaven or on earth where justice and compassion had won, or would win in a perhaps remote certain future" (p. 146). Forgiveness is one way to generate hope, that there is a greater force at work to help find meaning and healing in difficult situations. Levi was deprived of a spiritual connection which he said made the experience of survivors and guards after the holocaust, different and easier. According to Freeman [35], "What Levi had experienced, I suggest, might more appropriately be considered sin. It was a malady of the soul, and it could not become an object of change, of reconstruction. Hence the depth of the tragedy: here is what one might plausibly call religious experience, in a radically negative form, but with no religious resources available to allow the possibility of atonement or redemption" (p. 91). Finding a path beyond our own understanding is being open to the power of forgiveness. To realize a better way other than the harmfulness and hurt and pain of unforgiveness, "On some level, they are indeed signs of transcendence, of a going beyond both the confines of the present and evil that sometimes accompanies it. For Levi to tell this tragic story, in other words, he himself had to have known that there was a better way" [35], (p. 91). The forgiving of self is a matter of one's spiritual journey and belief system. Moral injury is the crisis of inner conflict plagued by irreconcilable notions of negative selfworth. Forgiveness and self-forgiveness in the crisis of moral injury has "to do with reconciling themselves not only to the personal past, but to the human condition itself, and the moral lateness that often characterizes it" [35], (p. 94). Reconciling with one's self may be one of the most important and deepest intimate personal-work a person can engage in. Seemingly, it can be part of a life-edited, one that is in constant revision and rewriting the personal narrative of healing from moral injury.

\section{Conclusion}

Moral injury is being pursued through the lens of many other disciplines other than psychology and theology, to find the most effective treatment and healing path for those who are suffering. As outlined in this paper, the psychological and emotional toll moral injury has on a person, makes it difficult to pathologize and categorize into a framework where one treatment is sufficient for everyone suffering with moral injury. Thus far the research shows inability to disclose the experiences of moral injury is one of the barriers that prevents healing [28]. Moral injury is a scar that shapes social, political and emotional life which impacts to tattily of the self [38]. With moral injury being a rather newly researched topic, and that several symptoms are present with moral injury, it appears that the main injury of the soul should be assessed and treated first which ultimately is a matter of spiritual care. 
Clinicians and therapist who incorporate spirituality into their practice should also be culturally sensitive and remain open to all areas of the client's life. A more holistic and integrative approach allows for openness and vulnerability as well as a trusting environment, one where the client feels safe and able to break through the barriers of non-disclosure [28].

In treating moral injury, inquiring about the client's beliefs and values is important related to the facts of the trauma as well as their thoughts and actions or how they were impacted and changed their outlook towards life. By bringing awareness to their personal narrative, "while the real past is fixed what happened, happened, and can't be changed the remembered past is fluid" [2], (p. 70). The remembered past has the ability to be altered and "They thicken with time, or at the very least, change" [2], (p. 68). Providing the opportunity to change the thought process through the lens of forgiveness, will impact the presenting symptoms and improve the overall well-being of the client. Through this framework, clients can experience improved cognitive processing, changes in their purview of the world and improve their belief system to live life with more meaning.

Competing interests: The authors of this paper declare no competing interests.

\section{References}

1. Shay, J., (1994). Achilles in Vietnam: Combat, trauma and the undoing of character. New York: Touchstone

2. Randall, W., (2019). In our stories lies our strengths: Aging, spirituality and narrative. Fredricton, CA. CARandall.

3. Cholbi, M. (2006). Belief attribution and the falsification of motive internalism. Philosophical Psychology, 19(5), 607-616.

4. Haidt, J., \&Bjorklund, F. (2008a). Social intuitionist answer six questions. In W. Sinnott-Armstrong (Ed.), Moral Psychology Vol. 2: The cognitive science of morality: Intuition and diversity (pp. 181-218). Cambridge, MA: MIT Press.

5. Jones, K. (2006). Metaethics and emotions research: A response to Prinz. Philosophical Explorations, 9(1), 45-53

6. Kennett, J., \& Fine, C. (2009). Will the real moral judgment please stand up? The implications of the social intuitionist models of cognition for meta-ethics and moral psychology. Ethical Theory and Moral Practice, 12(1), 77-96

7. Nichols, S. (2002). How psychopaths threaten moral rationalism: Is it irrational to be amoral? The Monist, 85(2), 285-304

8. Nichols, S. (2004). After objectivity: An empirical study of moral judgment. Philosophical Psychology, 17(1), 5-29

9. Prinz, J. (2007). The emotional construction of morals. New York: Oxford University Press.

10. Roskies, A. (2003). Are ethical judgments intrinsically motivational? Lessons from "Acquired Sociopathy". Philosophical Psychology, 16(1), 51 - 66.

11. Kohlberg, L., Levine, C., \& Hewer, A. (1983). Moral stages: A current formulation and a response to critics. New York: Basel.

12. Piaget, J. (1932/1965). The moral judgment of the child (M. Gabain, Trans.). New York: The Free Press.

13. Haidt, J., Koller, S. H.,\& Dias, M. G. (1993). Affect, culture, and morality, or is it wrong to eat your dog? Journal of Personality and Social Psychology, 65(4), 613-628

14. Inbar, Y., Pizarro, D. A., Knobe, J., \& Bloom, P. (2009). Disgust sensitivity predicts intuitive disapproval of gays. Emotion, 2009, 435-439

15. Schnall, S., Haidt, J., Clore, G. L., \& Jordan, A. H. (2008). Disgust as embodied moral judgment. Personality and Social Psychology Bulletin, 34(8), 1096.
16. Valdesolo, P., \&DeSteno, D. (2006). Manipulations of emotional context shape moral judgment. Psychological Science, 17(6), 476-477.

17. Wheatley, T., \&Haidt, J. (2005). Hypnotic disgust makes moral judgments more severe. Psychological Science, 16(10), 780-784

18. Kohlberg, L. (1984). The psychology of moral development: The nature and validity of moral stages. New York: Harper \& Row

19. Bucciarelli, M., Khemlani, S., \& Johnson-Laird, P. N. (2008). The psychology of moral reasoning. Judgment and Decision Making, 3(2), 121-139

20. Brock, R., N., Lettini, G., (2012). Soul repair: Recovering from moral injury after war. Boston: Beacon Press

21. Drescher, K. D., Foy, D. W., Kelly, C., Leshner, A., Schutz, K., Litz, B. (2011). An exploration of the viability and usefulness of the construct of moral injury in war veterans. Traumatology, $17(1), 8-13$

22. Litz, B.T., Stein, N., Delaney, E., Lebowitz, L., Nash, W.P., Silva, C., \&Maguen, S. (2009). Moral injury and moral repair in war veterans: A preliminary model and intervention strategy. Clinical Psychology Review, 29, 695-706

23. Shay, J., (2014). Moral injury. Psychoanalytic Psychology, 31(2), 182-191. Doi.org/10.1037/a0036090

24. Nash, W. P., Marino Carper, T. L., Mills, M. A., Au, T., Goldsmith, A., Litz, B. (2013). Psychometric evaluation of the moral injury events scale. Association of Military Surgeons of the United States: The Society of Federal Health Professionals. Vol 178, Issue 6, 646-652

25. Manguen, S., Litz, B. (2012). Moral injury in veterans of war. PTSD research quarterly, 23(1). Retrieved from http//www. ptsd.va.gov 2/23/2021

26. Tangney, J. P., Stuewig, J., Mashek, D. J., (2007). Moral emotions and moral behavior. Annual Review of Psychology, $58,345-372$.

27. Fry, B.G., J. Wickramaratna, W. Hodgson, P.Alewood, R.M. Kini, H. Ho \& W. Wüster (2002) Electrospray liquid chromatography/ mass spectrometry fingerprinting of Acanthophis (death adder) venoms: taxonomic and toxinological implications. Rapid Communications in Mass Spectrometry, 16: 600-608.

28. La Fleur, R., McDonald, M., Senecal, G., Coey, C., (2020). The impact of moral injury \& disclosure of military experiences of veterans. Journal of Humanistic Psychology. Doi. org/10.1177/0022167820972214

29. W Funder,J., M Carey, R., Mantero, F., Murad, M.H., Reincke, M., Shibata, H., Stowasser, M., F Young Jr, William., (2016). The Management of Primary Aldosteronism: Case Detection, Diagnosis, and Treatment: An Endocrine Society Clinical Practice Guideline. J Clin Endocrinol Metab. 101(5):1889-916. doi: 10.1210/jc.2015-4061

30. M. Phelps, R., Kerans, C., Da-Gama c, R.O.B.P., Jeremiah c, J., Hull, D., G. Loucks, R., (2015). Response and recovery of the Comanche carbonate platform surrounding multiple Cretaceous oceanic anoxic events, northern Gulf of Mexico. 54(5): 117144. https://doi.org/10.1016/j.cretres.2014.09.002

31. D. Berg, L., H. Huijbens, E., Larsen, H.G.,(2016).The Canadian Geographer Le Geographe Canadien. 60(2): 168-180. https:// doi.org/10.1111/cag.12261

32. R Levi-Montalcini. (1987). The nerve growth factor 35 years later. Science, 4;237(4819):1154-62. doi: 10.1126/ science. 3306916

33. Levi, P. (1989). The drowned and the saved. New York: Vintage 
34. Buber, M., (1970). I and thou: Martin Buber-A new translation, with prologue and notes by Walter Kaufmann. New York: Simon and Schuster

35. Freeman, M. (2010). Hindsight: The promise and peril of looking backwards. New York: Oxford Gillian,

36. Chang, C.M., Corey, C.G., Rostron, B.L., \& Apelberg, B.J., (2015). Systematic review of cigar smoking and all cause and smoking related mortality. 24 (4); 15:390. doi: 10.1186/s12889015-1617-5.
37. Karen, R. (2001). The forgiving self: The road from resentment to connection. New York: Doubleday

38. Ramsay, N.J., \& Doehring, C., (2019). Military moral injury and spiritual care. St. Louis. Chalice Press. 